\title{
POTENSI TANAMAN KANGKUNG AIR DALAM MEMPERBAIKI KUALITAS LIMBAH CAIR RUMAH POTONG AYAM
}

\section{POTENTIAL OF WATER SPINACH PLANT TO IMPROVE THE QUALITY OF CHICKEN SLAUGHTERHOUSE LIQUID WASTE}

\author{
Muhammad Najib Ngirfani ${ }^{1)}$, Rizqa Puspitarini ${ }^{2)}$ \\ ${ }^{1), 2)}$ Program Studi Teknik Lingkungan Politeknik Muhammadiyah Magelang \\ Email: m.najib.ng@gmail.com \\ diterima : 6 Februari 2020; dipublikasi : 30 Maret 2020 \\ DOI: $10.32528 /$ bioma.v5i1.2897
}

\begin{abstract}
ABSTRAK
Penelitian ini bertujuan mengetahui potensi tanaman kangkung air dalam memperbaiki kualitas limbah cair RPA dengan mengkaji pengaruh jumlah tanaman kangkung air (Ipomoea aquatica Forsk.) terhadap efisiensi penurunan COD dan BOD limbah cair Rumah Pemotongan Ayam (RPA). Penelitian ini merupakan penelitian kuantitatif Rancangan Acak Lengkap (RAL) dengan 3 ulangan. Variabel bebas pada penelitian ini adalah jumlah tanaman kangkung air dengan 5 variasi yaitu 0 tanaman $(\mathrm{O}), 2$ tanaman (A), 4 tanaman (B), 6 tanaman (C) dan 8 tanaman (D) dengan variabel terikat adalah parameter kualitas limbah cair RPA yaitu COD dan BOD. Analisis data dilakukan dengan uji ANOVA dilanjutkan dengan uji lanjut tukey HSD. Hasil penelitian menunjukkan bahwa kangkung air mampu menurukan COD dan BOD limbah cair RPA. Jumlah tanaman kangkung air berpengaruh terhadap efisiensi penurunan COD dan BOD. Jumlah tanaman kangkung air paling efektif menurunkan COD dan BOD limbah cair RPA adalah 4 tanaman kangkung air dalam 3 liter limbah cair.
\end{abstract}

Kata kunci: Fitoremidiasi, Limbah Cair RPA, Kangkung Air, COD, BOD

\begin{abstract}
This research aims to find the potential of water spinach plants improve the quality of chicken slaughterhouse liquid waste by examinie the effect of the amount of water spinach plants (Ipomoea aquatica Forsk.) on the efficiency of COD and BOD reduction of chicken slaughterhouse liquid waste. This research is quantitative research with a completely randomized design (CRD) with 3 replicates. The independent variable in this research is the number of water spinach plants with 5 variations, that is 0 plants $(O)$, 2 plants (A), 4 plants (B), 6 plants (C) and 8 plants (D).. The data was analyzed by the ANOVA test and then followed by the tukey HSD test. The results of this research show that water spinach able to reduce COD and BOD of chicken slaughterhouse liquid waste. The number of water spinach plants affect the efficiency of COD and BOD reduction. The most effective to reduce COD and BOD chicken slaughterhouse liquid waste is 4 water spinach plants in 3 liters of liquid waste.
\end{abstract}

Keywords: Phytoremidiation, Slaughterhouse Liquid Waste, Water Spinach Plants, COD, BOD 


\section{PENDAHULUAN}

Rumah Pemotongan Ayam (RPA) merupakan salah satu industri perternakan yang mengelola pemotongan ayam hidup dan mengolah menjadi daging bertulang (karkas) ayam siap konsumsi (Susetyo, 2017). Proses pemotongan ayam mengasilkan dua jenis limbah, yaitu limbah padat dan limbah cair, diantara kedua jenis limbah tersebut limbah cair merupakan limbah yang sangat berdampak terhadap lingkungan. Hal tersebut disebabkan kebanyakan usaha pemotongan ayam adalah usaha kecil dan menengah, sehingga RPA yang ada pada umumnya tidak memiliki Instalasi Pengolah Air Limbah (IPAL) dikarenakan mahalnya alat yang dibutuhkan, yang pada akhirnya limbah cair RPA langsung dibuang ke lingkungan atau perairan terbuka tanpa dilakukan pengolahan. Air limbah sampai dengan saat ini sebagian besar masuk ke badan air penerima lewat drainase atau saluran air tanpa diolah terlebih dahulu (Iswanto, 2010).

Limbah cair yang dihasilkan oleh RPA bersifat organik berasal dari air bekas cucian ayam, darah ayam, dan sludge (endapan lemak) sehingga memiliki BOD (Biological Oxygen Demand), COD (Chemical Oxygen Demand), TSS (Total Suspended Solids), minyak dan lemak yang tinggi. BOD merupakan parameter yang dapat digunakan untuk memperkirakan jumlah oksigen yang diperlukan oleh mikroorganisme untuk memecah atau mendegradasi bahan organik di perairan, sehingga dapat menggambarkan jumlah kandungan bahan organik yang mudah urai yang ada di dalam perairan tersebut. COD adalah parameter yang digunakan untuk memperkirakan jumlah total bahan organik yang terkandung di perairan, baik bahan organik yang mudah urai atau didegradasi maupun yang sulit didegradasi. Gambaran jumlah bahan organik yang mudah didegradasi dengan yang sulit didegradasi (persisten) dapat diketahui dengan membandingkan nilai BOD dan COD. BOD dan COD dapat digunakan sebagai parameter pencemaran perairan, khususnya sebagai penduga pencemaran bahan organik (Atima, 2015). Pembuangan air limbah (Efluen) yang mengandung nutrien bahan organik yang tinggi ke perairan akan menimbulkan eutrofikasi dan mengancam ekosistem aquatik (Laksono, 2010)

Permasalahan di atas tentunya diperlukan solusi agar dapat mengurangi dampak limbah cair RPA terhadap lingkungan. Teknik pengolahan limbah cair yang efektif dan efisien yang dapat digunakan salah satunya adalah Fitoremidiasi. Fitoremediasi adalah proses menghilangkan polutan dari tanah atau perairan 
menggunakan tumbuhan (Rondonuwu, 2014). Teknik fitoremediasi dianggap teknologi yang inovatif, ekonomis dan relatif aman terhadap lingkungan (Sidauruk dan Patricius, 2015). Proses fitoremediasi terjadi berawal dari akar tumbuhan yang menyerap bahan pencemar yang ada di dalam air, selanjutnya melalui proses transportasi tumbuhan, air yang mengandung bahan pencemar dialirkan ke seluruh tubuh tumbuhan, sehingga air menjadi bersih dari pencemar. Tumbuhan di dalam proses remidiasi lingkungan tercemar dapat berperan langsung maupun tidak langsung. Tumbuhan belum tentu berperan aktif dalam penyisihan bahan pencemar, kemungkinan tumbuhan tersebut berperan pasif atau secara tidak langsung (Surtikanti, 2011). Tanaman yang digunakan dapat disesuaikan dengan karakteristik limbah yang akan diolah. Ada beberapa tanaman yang dapat digunakan, contohnya adalah kangkung, eceng gondok, bambu air, hydrilla, kayu apu, kiambang, dan lainnya (Rahadian, 2017).

Kangkung air tumbuh merambat dan mengapung di atas air dan sering digunakan sebagai sayur. Tanaman ini banyak ditemukan di wilayah Asia Tenggara, India dan Cina bagian Tenggara. Kangkung air dapat mengurangi bahan pencemar air limbah roti, tekstil, industri dan obat-obatan (Hidayat dalam Rosita, 2013). Menurut Rosita (2013) Tanaman kangkung merupakan tanaman yang dapat memanfaatkan kandungan nutrien buruk perairan untuk dimanfaatkan dalam proses hidupnya. Kangkung air dapat menghasilkan oksigen dan menyerap bahan pencemar yang masuk ke perairan seperti nitrogen dan fosfor. Hal tersebut yang membuat tumbuhan kangkung dapat digunakan untuk fitoremediasi (Rosita, 2013). Menurut Natalina (2013) tanaman kangkung air dapat menurunkan kadar COD sebesar 86,2\%, kadar BOD (biochemical oxygen demand) sebesar $86,7 \%$, pada limbah cair tahu.

Tumbuhan air yang berada di air limbah dapat menyerap zat organik yang terkandung di dalamnya. Tumbuhan air yang ada semakin banyak, maka bahan organik yang terserap semakin banyak juga, sehingga bahan organik yang harus diurai oleh mikroorganisme semakin sedikit (Fachrurozi, 2010).

Tanaman kangkung air memiliki tingkat pertumbuhan yang tidak terlalu pesat dan memiliki tingkat penutupan/naungan yang rendah, sehingga tidak mengganggu kondisi lingkungan dan makhluk hidup di bawahnya. Selain itu tanaman kangkung air dapat dikonsumsi dan juga memiliki nilai ekonomi. Pengolahan limbah cair RPA 
dengan tanaman kangkung air secara fitoremidiasi diharapkan mampu menjadi salah satu alternatif pengolahan limbah cair RPA yang efektif dan terjangkau secara finansial.

\section{METODE}

Penelitian dilakukan di tempat percobaan/green house Politeknik Muhammadiyah Magelang dan pengujian kualitas limbah cair dilakukan di laboratorium lingkungan Institut Teknologi Yogyakarta (ITY). Limbah cair RPA diambil dari RPA di Muntilan Magelang.

\section{Variabel Penelitian}

Variabel bebas penelitian ini adalah jumlah tanaman kangkung air, yaitu 0 tanaman (O), 2 tanaman (A), 4 tanaman (B), 6 tanaman (C) dan 8 tanaman (D) dengan variabel terikat berupa kadar COD dan BOD limbah cair RPA. Menurut Apsari (2018) semakin banyaknya jumlah tanaman yang kontak dengan limbah maka tanaman mampu untuk menyerap bahan-bahan organik yang terdapat pada limbah yang selanjutnya digunakan untuk pertumbuhan.

Tabel 1. Rancangan Percobaan

\begin{tabular}{cccc}
\hline $\begin{array}{c}\text { Jumlah Tanaman } \\
\text { Kangkung Air }\end{array}$ & $\mathbf{1}$ & Pengulangan \\
\hline $0(\mathrm{O})$ & $\mathrm{O} 1$ & $\mathrm{O} 2$ & $\mathbf{3}$ \\
$2(\mathrm{~A})$ & $\mathrm{A} 1$ & $\mathrm{~A} 2$ & $\mathrm{O} 3$ \\
$4(\mathrm{~B})$ & $\mathrm{B} 1$ & $\mathrm{~B} 2$ & $\mathrm{~A} 3$ \\
$6(\mathrm{C})$ & $\mathrm{C} 1$ & $\mathrm{C} 2$ & $\mathrm{C} 3$ \\
$8(\mathrm{D})$ & $\mathrm{D} 1$ & $\mathrm{D} 2$ & $\mathrm{D} 3$ \\
\hline
\end{tabular}

\section{Alat dan Bahan}

Alat yang digunakan berupa botol sampel, bak plastik besar, baskom plastik, timbangan analitik, penggaris dan peralatan uji laboratorium parameter uji COD dan BOD. Bahan yang digunakan adalah Limbah cair RPA usia 0 hari, tanaman kangkung air dan bahan uji laboratorium parameter uji COD dan BOD.

\section{Pengambilan Limbah Cair RPA}

Limbah cair RPA dengan usia 0 hari diambil langsung dari saluran pembuangan limbah cair RPA sejumlah 55 liter pada aliran bak pembuangan. 
Pengambilan limbah cair dilakukan dengan memotong di saluran pembuangan sebelum aliran dibuang ke perairan terbuka. Limbah cair ditampung pada sebuah wadah (bak tabung) besar dengan volume \pm 65 liter agar seluruh limbah menyatu/homogen.

\section{Pelaksanaan}

Penelitian ini menggunakan 15 buah baskom plastik hitam berdiameter $31 \mathrm{~cm}$ dengan ketinggian $25 \mathrm{~cm}$. Tanaman yang digunakan dalam penelitian ini adalah kangkung air yang diambil di kolam yang berlokasi di Muntilan Magelang. Tanaman kangkung air yang digunakan berupa tanaman baru yang tumbuh pada ruas batang pokok dengan bobot basah tanaman \pm 5 gram setiap tanaman dan jumlah dauh 4-5 helai. Tanaman atau batang tersebut dipotong/dipisahkan dari batang pokok kemudian dibersihkan dari lumpur yang menempel dan tanaman kangkung air ditimbang bobot basah, diukur tinggi tanaman dan dihitung jumlah daunnya.

Wadah ditempatkan secara acak pada tempat khusus yang cukup cahaya matahari dan terlindung dari air hujan agar seluruh perlakuan memperoleh fasilitas lingkungan yang sama. Pengacakan dilakukan dengan sistem undian. Setiap wadah diletakkan kangkung air sesuai dengan perlakuan yang diinginkan kemudian dituangkan limbah cair RPA secara bersamaan dengan volume 3 liter limbah cair, sehingga tersusun 15 wadah (1 jenis tanaman, 5 variasi jumlah batang dan 3 kali ulangan). Dasar wadah diletakan 3 buah batu dengan diameter ukuran $\pm 5 \mathrm{~cm}$ untuk setiap tanaman yang berfungsi untuk menghimpit akar tanaman agar bisa berdiri tegak.

Penelitian dilaksanakan selama 10 hari. Kualitas limbah cair diuji sebelum dan sesudah perlakuan, yaitu hasil pengujian di hari pertama pelaksanaan sebagai data sebelum perlakuan dan hasil pengujian pada hari ke 10 adalah data sesudah perlakuan.

\section{Pengolahan dan Analisis Data}

Data yang diperoleh dari setiap parameter (BOD dan COD) dihitung prosentase efisiensi penurunannya kemudian diuji menggunakan uji statistik ANOVA dilanjutkan uji tukey HSD dengan menggunakan bantuan aplikasi SPSS. 


\section{HASIL DAN PEMBAHASAN}

\section{Limbah Cair RPA Sebelum Perlakuan}

Hasil pengujian kulitas limbah cair RPA sebelum perlakuan meliputi kadar COD dan BOD dapat dilihat pada Tabel 2.

Tabel 2. Kualitas Limbah Cair RPA Sebelum Perlakuan

\begin{tabular}{cccc}
\hline Parameter & Satuan & Baku Mutu & Hasil \\
\hline COD & $\mathrm{mg} / \mathrm{L}$ & 200 & 276.14 \\
BOD & $\mathrm{mg} / \mathrm{L}$ & 100 & 151.56 \\
\hline
\end{tabular}

Keterangan: Baku mutu limbah cair sesuai Peraturan

Pemerintah Daerah Provinsi Jawa Tengah No.5 tahun 2012

Terlihat dari Tabel 2. dapat diketahui bahwa nilai COD dan BOD limbah cair RPA melebihi baku mutu limbah cair yang telah ditetapkan oleh pemerintah. Hal ini berarti bahwa limbah cair RPA memiliki kandungan bahan organik yang tinggi, sebagaimana menurut Said (2005), limbah cair organik yang dihasilkan industri RPA memiliki parameter chemical oxygen demand (COD), serta kandungan zat organik yang sangat tinggi. Kondisi limbah cair yang demikian tentunya akan berdampak negatif ketika langsung dibuang ke lingkungan atau ke badan air terbuka. Dampak yang ditimbulkan antara lain adalah penuruan DO, kenaikan suhu, ketidak stabilan pH serta bau busuk yang mengganggu kehidupan air dan lingkungan sekitar bahkan mampu menyebabkan punahnya hewan atau tumbuhan air.

\section{Limbah Cair RPA Sesudah Perlakuan}

Hasil pengukuran parameter kualitas limbah cair sesudah perlakuan tersaji pada Tabel 3.

Tabel 3. Kualitas Limbah Cair RPA Sesudah Perlakuan

\begin{tabular}{|c|c|c|}
\hline Perlakuan ${ }^{1)}$ & COD & BOD \\
\hline Rata-Rata O & 156.49 & 96.84 \\
\hline Rata-Rata A & 98.29 & 56.00 \\
\hline Rata-Rata B & 80.85 & 45.85 \\
\hline Rata-Rata C & 74.58 & 42.06 \\
\hline Rata-Rata D & 69.40 & 40.50 \\
\hline Baku Mutu ${ }^{2)}$ & 200 & 100 \\
\hline
\end{tabular}


Keterangan: Perlakuan ${ }^{1)}$ Jumlah tanaman kangkung air,

$O=0$ tanaman, $A=2$ tanaman, $B=4$ tanaman, $C=6$ tanaman,

D = 8 tanaman

Baku Mutu ${ }^{2)}$ Baku Mutu Limbah Cair RPA sesuai Peraturan Pemerintah

Daerah Provinsi Jawa Tengah No.5 tahun 2012

Berdasarkan Tabel 3. dapat dilihat bahwa kualitas limbah cair semakin baik setelah diberikan perlakuan. Hal tersebut ditunjukkan dengan penurunan kadar COD dan BOD. Kadar COD dan BOD yang diberikan perlakuan dengan tanaman kangkung air hasilnya telah berada di bawah baku mutu yang ditetapkan. Tabel 3. juga menunjukkan bahwa dari hasil pengujian terdapat perbedaan nilai BOD dan COD. COD memiliki nilai lebih tinggi dari BOD dikarenakan BOD hanya menggambarkan kandungan bahan organik yang mampu didegradasi oleh mikroorganisme, sedangkan COD menggambarkan seluruh bahan organik baik yang mudah didegradasi maupun yang sulit didegradasi oleh mikroorganisme. Uji COD menggunakan bahan kimia berupa oksidator kuat kalium bikromat pada kondisi asam dan panas dengan katalisator perak sulfat, sehingga segala macam bahan organik akan teroksidasi (Boyd dalam Atima, 2015).

\section{Efisiensi Penuruan COD}

Hasil penghitungan efisiensi penuruan COD tersaji pada Tabel 3.

Tabel 3. Efisiensi Penurunan COD

\begin{tabular}{cccccc}
\hline \multirow{2}{*}{ Ulangan } & \multicolumn{5}{c}{ Efisiensi Penurunan COD (\%) } \\
& O & A & B & C & D \\
\hline 1 & 46.10 & 65.11 & 71.55 & 73.18 & 75.35 \\
2 & 45.40 & 62.50 & 71.23 & 71.95 & 73.90 \\
3 & 38.49 & 65.60 & 69.38 & 73.85 & 75.35 \\
\hline \multirow{2}{*}{ Rata-Rata } & $\mathbf{4 3 . 3 3}$ & $\mathbf{6 4 . 4 0}$ & $\mathbf{7 0 . 7 2}$ & $\mathbf{7 2 . 9 9}$ & $\mathbf{7 4 . 8 7}$ \\
& (a) & (b) & (c) & (c) & (c)
\end{tabular}

Keterangan: Huruf kecil yang sama menunjukkan tidak ada beda yang nyata antara rata-rata satu dengan yang lain pada taraf kepercayaan $95 \%$ uji lanjutan tukey 
Hasil analisis ANOVA yang tersaji pada Tabel 3. diperoleh nilai signifikansi (P) sebesar 0.000 . Nilai $\mathrm{P}(0,000)$ yang lebih kecil daripada nilai alfa $(0,05)$ berarti bahwa $\mathrm{H}_{1}$ diterima atau ada perbedaan yang nyata rata-rata efisiensi penurunan pada salah satu atau lebih kelompok data perlakuan. Hasil uji ANOVA secara singkat dapat diartikan bahwa perlakuan variasi jumlah tanaman kangkung air berpengaruh terhadap efisiensi penurunan COD limbah cair RPA. Hal tersebut mengartikan bahwa tanaman kangkung air memiliki kemampuan menurunkan COD limbah cair RPA. Efisiensi penurunan COD semakin meningkat seiring dengan bertambahnya jumlah tanaman pada perlakuan dengan efisiensi tertinggi pada perlakuan D (8 tanaman kangkung air) sebagaimana grafik yang ditunjukan pada Gambar 1.

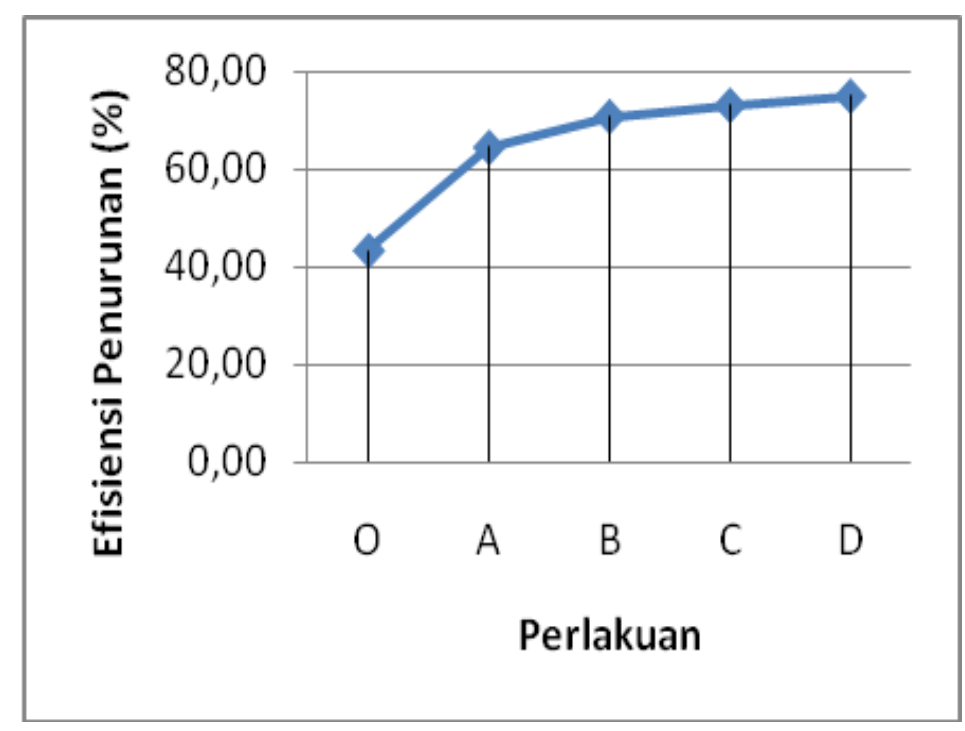

Gambar 1. Efisiensi penurunan COD

Pengujian COD adalah uji untuk mengetahui kandungan bahan organik yang terdapat pada limbah cair. Hal tersebut mengartikan bahwa kadar COD berbanding lurus dengan jumlah bahan organik yang terkandung dalam suatu limbah, dimana kandungan bahan organik semakin tinggi maka nilai COD pun meningkat, begitu pula sebaliknya. Penurunan COD ada hubungannya dengan menurunnya kandungan bahan organik dalam limbah cair RPA, suplai oksigen oleh tanaman kangkung air ke dalam limbah cair dan menyerap hasil dekomposisi bahan organik. Menurut Suardhana, (2009) tanaman air mampu menyerap bahan organik dalam bentuk ion hasil degradasi mikroorganisme dan membebaskan oksigen yang digunakan oleh mikroorganisme untuk proses oksidasi. 
Tumbuhan dapat menyerap pencemar sejauh akar tanaman tersebut tumbuh. Mikroorganisme yang tumbuh pada akar tanaman ini semakin efektif dalam menurunkan nilai COD karena jumlah mikroorganisme semakin banyak dan mikroorganisme tersebut semakin mampu beradaptasi dengan lingkungan tersebut (Djo, 2017). Kerjasama antara tumbuhan air dengan mikroorganisme mampu menurunkan kandungan pencemar dalam air. Proses diawali dengan air limbah dioksidasi melepaskan energi yang dipakai oleh mikroorganisme untuk pemeliharaan dan pembentukan sel baru menuju pada fase eksponensial, yaitu suatu kondisi terjadi peningkatan jumlah sel karena mikroorganisme mengalami fase pertumbuhan. Pada fase ini, jumlah mikroorganisme mencapai jumlah maksimal sehingga limbah organik dapat didegrasi dengan maksimal (Djo, 2017). Menurut Supradata (2005) bahan organik yang terdapat didalam air limbah akan diurai atau dirombak oleh mikroorganisme menjadi senyawa lebih sederhana dan akan dimanfaatkan oleh tumbuhan sebagai nutrisi, sedangkan sistem perakaran tumbuhan air akan menghasilkan oksigen yang dapat digunakan sebagai sumber energi/katalis untuk rangkaian proses metabolisme bagi kehidupan mikroorganisme.

Berdasarkan hasil uji lanjutan tukey HSD meskipun secara kuntitatif memiliki nilai yang berbeda, namun pada perlakuan $\mathrm{B}, \mathrm{C}$ dan $\mathrm{D}$ tidak terdapat perbedaan yang nyata efisiensi penurunan COD. Tidak adanya perbedaan yang nyata efisiensi penurunan COD pada perlakuan $\mathrm{B}, \mathrm{C}$ dan $\mathrm{D}$ dapat terjadi diduga karena perbedaan fisiologi tanaman dan tingkat kerapatan tanaman. Setiap tanaman memilki kondisi fisiogis yang berbeda-beda meskipun dalam satu famili bahkan spesies. Berkaitan dengan remidiasi limbah organik perbedaan itu terjadi antara lain pada kemapuan tanaman dalam menyerap unsur hara dan transpirasi. Berkaitan dengan kerapatan tanaman, menurut Ulfin (2005) pada kerapatan rendah penguapan berlangsung lebih sempurna sehingga tercipta sifat alami pertumbuhan yang lebih bagus. Tanaman yang terlalu rapat, evaporasi dan pertumbuhannya cenderung lebih lambat. Hal ini berpengaruh terhadap proses penyerapan unsur hara dan fotosintesis. 


\section{Efisiensi Penuruan BOD}

Tabel 4. Efisiensi Penurunan BOD

\begin{tabular}{cccccc}
\hline \multirow{2}{*}{ Ulangan } & \multicolumn{5}{c}{ Efisiensi Penurunan BOD (\%) } \\
& O & A & B & C & D \\
\hline 1 & 40.10 & 63.77 & 70.98 & 72.37 & 73.50 \\
2 & 34.99 & 61.74 & 70.09 & 71.13 & 72.42 \\
3 & 33.23 & 63.65 & 68.18 & 73.25 & 73.92 \\
\hline \multirow{2}{*}{ Rata-Rata } & $\mathbf{3 6 . 1 0}$ & $\mathbf{6 3 . 0 5}$ & $\mathbf{6 9 . 7 5}$ & $\mathbf{7 2 . 2 5}$ & $\mathbf{7 3 . 2 8}$ \\
& (a) & (b) & (c) & (c) & (c) \\
\hline
\end{tabular}

Keterangan: Huruf kecil yang sama menunjukkan tidak ada beda yang nyata antara rata-rata satu dengan yang lain pada taraf kepercayaan $95 \%$ uji lanjutan tukey

Berdasarkan hasil analisis ANOVA efisiensi penurunan BOD diperoleh nilai signifikansi $(\mathrm{P})$ sebesar 0.000 . Nilai $\mathrm{P}(0,000)$ yang lebih kecil daripada nilai alfa $(0,05)$ berarti bahwa $\mathrm{H}_{1}$ diterima atau ada perbedaan yang nyata rata-rata efisiensi penurunan BOD pada salah satu atau lebih kelompok data perlakuan. Hasil uji ANOVA secara singkat dapat diartikan bahwa perlakuan variasi jumlah tanaman kangkung air berpengaruh terhadap efisiensi penurunan BOD limbah cair RPA. Hal ini juga mengartikan bahwa tanaman kangkung air memiliki kemampuan menurunkan BOD limbah cair RPA. Efisiensi penurunan BOD semakin meningkat seiring dengan bertambahnya jumlah tanaman pada perlakuan dengan efisiensi tertinggi pada perlakuan D (8 tanaman kangkung air) sebagaimana grafik yang ditunjukan pada Gambar 2.

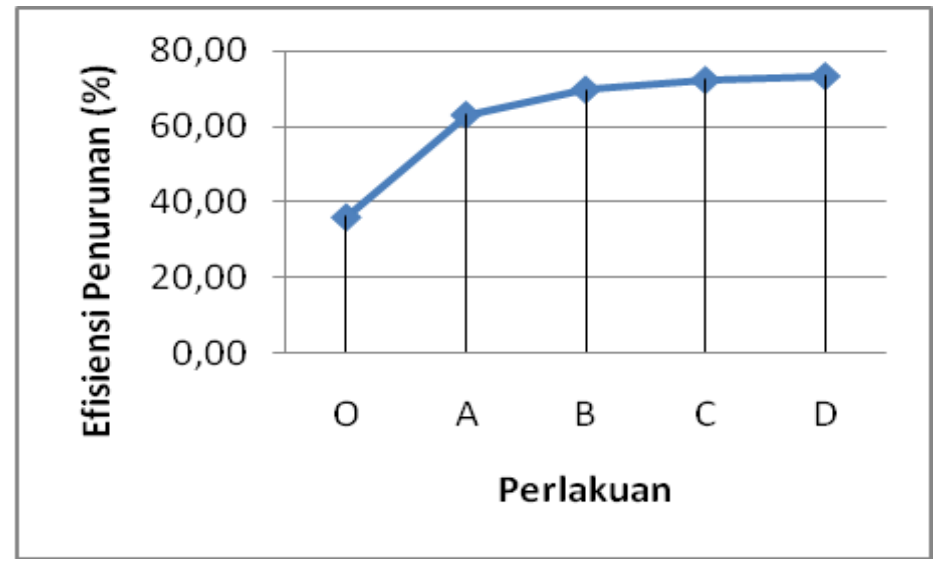

Gambar 2. Efisiensi Penurunan BOD 
Hasil analisis pada efisiensi penurunan BOD memilki kemiripan dengan analisis efisensi penurunan COD. Pengujian kadar BOD pada dasarnya memiliki tujuan yang sama dengan pengujian COD yaitu untuk mengetahui jumlah bahan organik yang terkandung dalam sebuah limbah cair. Nilai BOD berbanding lurus dengan nilai COD (Padmaningrum, 2014). BOD merupakan jumlah oksigen terlarut yang dibutuhkan oleh bakteri pengurai untuk mendegradasi bahan pencemar organik di dalam air. Menurut Yudo (2010) semakin besar nilai BOD di dalam perairan, menunjukkan bahwa kandungan bahan organik di dalam air juga tinggi.

Kangkung air yang berada pada limbah cair menyerap zat organik yang terkandung dalam limbah tersebut. Proses adsorbsi zat-zat yang terdapat di dalam media tanam dilakukan oleh ujung-ujung akar dengan jaringan meristem karena adanya gaya tarik menarik oleh molekul-molekul air yang ada pada tumbuhan (Rusyani, 2014). Fachrurozi et al. (2010) mengungkapkan nilai BOD dipengaruhi oleh adanya tumbuhan yang menutupi permukaan air limbah. Semakin banyak tumbuhan air pada limbah cair, maka bahan organik yang terserap semakin banyak pula, sehingga bahan organik yang harus didegradasi oleh mikroorganisme semakin sedikit. Kondisi ini menyebabkan kandungan oksigen dalam limbah cair semakin tinggi. Kandungan oksigen terlarut juga semakin banyak karena adanya suplai oksigen dari hasil fotosintesis tumbuhan. Jadi semakin banyak tumbuhan, maka nilai BOD semakin kecil yang berarti semakin baik kualitas air limbah tersebut.

Berdasarkan hasil uji lanjutan tukey HSD meskipun secara kuntitatif memiliki nilai yang berbeda, namun pada perlakuan $\mathrm{B}, \mathrm{C}$ dan $\mathrm{D}$ tidak terdapat perbedaan yang nyata efisiensi penurunan BOD. Hasil tersebut juga memiliki kemiripan dengan hasil analisis yang dilakukan pada efisiensi penurunan COD. Hal tersebut dapat terjadi diduga disebabkan oleh faktor yang sama seperti pada analisis efisiensi penurunan COD.

\section{KESIMPULAN DAN SARAN}

Tanaman kngkung air (Ipomoea aquatica Forsk.) memiliki kemampuan memperbaiki kulitas limbah caiar RPA dengan menurunkan COD dan BOD limbah cair. Jumlah tanaman kangkung air (Ipomoea aquatica Forsk.) berpengaruh signifikan terhadap efisiensi penurunan COD dan BOD limbah cair RPA. Jumlah tanaman 
kangkung air paling efektif menurunkan COD dan BOD limbah cair RPA adalah 4 tanaman kangkung air dalam 3 liter limbah cair.

\section{DAFTAR PUSTAKA}

Apsari, Lela, Eko Kusumawati, Dwi Susanto. (2018). Fitoremediasi Limbah Cair Laundry Menggunakan Melati Air (Echinodorus palaefolius) dan Eceng Padi (Monochoria vaginalis). Bioprospek. 13 (2) 2018 29-38

Atima, Wa. (2015). BOD dan COD Sebagai Parameter Pencemaran Air dan Baku Mutu Air Limbah. Jurnal Biology Science \& Education. Vol. 4 No. 1. IAIN Ambon

Djo, Yuliana Herman, Dwi Adhi S, Iryanti F.S., Wahyu D. (2017). Fitoremediasi Limbah Cair UPT Laboratorium Analitik Universitas Udayana Menggunakan Tanaman Eceng Gondok (Eichhornia crassipes) Ditinjau dari Penurunan Nilai COD dan Kandungan Logam Berat Cu dan Cr. Skripsi. Jurusan kimia FMIPA Universitas Udayana, Bukit Jimbaran. Bali

Fachrurozi M, Utami LB, Suryani D. (2010). Pengaruh Variasi Biomassa Kiapu. Terhadap Penurunan Kadar BOD, COD, dan TSS Limbah Cair Tahu di Dusun Klero Sleman Yogyakarta. Jurnal Kesmas. 4(1):1-16.

Iswanto, Bambang. (2010). Teknologi Elektrokoagulasi Hasil Penelitian untuk

Pengolahan Limbah Domestik. Indonesian Journal of Urban and Environmental Technology 5(4) : 113-136

Laksono, M.S. dan Kariana, M. (2010). Peningkatan Produktivitas dan Kinerja Lingkungan dengan Pendekatan Green Productivity Pada Rumah Pemotongan Ayam. Jurnal Fakultas Teknologi Industri. Institut Teknologi Sepuluh Nopember Surabaya

Maulidiya, Ida. (2018). Produktivitas Kangkung Air (Ipomoea aquatica) dari Sumber Nutrien Air Limbah Tahu. Skripsi. Departemen Manajemen Sumberdaya Perairan Fakultas Perikanan Dan Ilmu Kelautan Institut Pertanian Bogor.Bogor Natalina. (2013). Penggunaan enceng gondok (Eichornia crassipes (Mart) Solms) dan kangkung air (Ipomoea aquatica Forsk) dalam perbaikan kualitas air limbah industri tahu. Prosiding Seminar Nasional Sains dan Teknologi V Satek dan Indonesia Hijau (Satek Unila), pp: 980-988, ISBN : 978-979- 8510-71-7. 
Peraturan Pemerintah Daerah Provinsi Jawa Tengah No. 5 Tahun 2012 Perubahan Atas Peraturan Daerah Provinsi Jawa Tengah Nomor 10 Tahun 2004 Tentang Baku Mutu Air Limbah. 9 April. 2012. Lembaran Provinsi Jawa Tengah Tahun 2012. Jawa Tengah

Rahadian, R, Endro S, Sri S. (2017). Efisiensi Penurunan COD dan TSS dengan Fitoremidiasi menggunakan Tanaman Kayu Apu (Pistia stratiotes), Studi Kasus: Limbah Cair Laundry. Jurnal TL, Vol. 6, No. 3. Undip

Rondonuwu, S.B. (2014). Fitoremediasi limbah merkuri menggunakan tanaman dan sistem reaktor. Jurnal Ilmiah Sains 14 (1): 52-59.

Rosita, Enny, Winny R.M., Andi Z. (2013). Efektivitas Fitoremediasi Kangkung Air (Ipomoea aquatica Forsk) terhadap Penyerapan Orthopospat Pada Detergen Ditinjau Dari Detensi Waktu dan Konsentrasi Orthopospat. Jurnal Teknik Kimia USU, Vol. 4, No. 1.

Rusyani, Rini. (2014). Potensi Tumbuhan Genjer Sebagai Agen Fitoremediasi Pada Limbah Yang Mengandung Logam Timbal (Pb). Skripsi. Universitas Negeri Gorontalo

Sidauruk, L. dan Sipayung, P. (2015). Fitoremediasi lahan tercemar di kawasan industri Medan dengan tanaman hias. Jurnal Pertanian Tropik 2 (2): 178-186.

Suardhana I.W. (2009). Pemanfaatan Eceng Gondok (Eichorria crassipes (Mart) Solm) Sebagai Teknik Alternatif dalam Pengolahan Biologis Air Limbah Asal Rumah Pmotongan Hewan (RPH) Pesanggaran. Denpasar Bali. Jurnal Biologi : 9 (6) :759-760.

Supradata. (2005). Pengolahan Limbah Domestik Menggunakan Tanaman Hias (Cyperusalternifolius L.) Dalam Sistem Lahan Basah Buatan Aliran Bawah Permukaan (SSF-Wetlands). Desertasi. UNDIP. Semarang

Surtikanti, H.K. 2011. Toksikologi Lingkungan dan Metode Uji Hayati. Rizqi Press . Bandung

Susetyo, Joko. (2017). Analisis Produktivitas dengan Metode Objective Matrix Dan Green Productivity di Rumah Pemotongan Ayam. Jurnal Seminar Nasional IENACO.

Ulfin I, Widya W. (2005). Study penyerapan kromium dengan Ki Apu (Pistia stratiotes L.). Jurnal Akta Kimindo. 1(1):41-48. 
Yudo, S. (2010). Kondisi kualitas air sungai Ciliwung di wilayah DKI Jakarta ditinjau dari parameter organik, amoniak, fosfat, deterjen dan bakteri coli. Jurnal Akuakultur Indonesia. 6:34-42 